\title{
Environmentally Assisted Cracking Initiation in High-Temperature Water
}

\author{
Anna Hojná (D) \\ ÚJV Group, Centrum výzkumu Řež, Řež 130, 25068 Husinec, Czech Republic; anna.hojna@cvrez.cz
}

check for updates

Citation: Hojná, A. Environmentally Assisted Cracking Initiation in High-Temperature Water. Metals 2021 11, 199. https://doi.org/10.3390/ met11020199

Academic Editor: Yun-Jae Kim Received: 28 December 2020

Accepted: 19 January 2021

Published: 22 January 2021

Publisher's Note: MDPI stays neutral with regard to jurisdictional claims in published maps and institutional affiliations.

Copyright: (C) 2021 by the author. Licensee MDPI, Basel, Switzerland. This article is an open access article distributed under the terms and conditions of the Creative Commons Attribution (CC BY) license (https:// creativecommons.org/licenses/by/ $4.0 /)$.

\begin{abstract}
Environmentally assisted cracking (EAC) is a very complex process that develops in materials that involve combining actions of environment and tensile loading. Crack initiation is the least explored stage and is not clearly defined. For this paper, current knowledge of crack initiation mechanisms was reviewed for three types of commercial structure materials exposed to high-temperature (HT) water coolants of power plants, namely ferritic low-alloy (LAS) and carbon (CS) steels, austenitic stainless (AS) steels, and nickel-based alloys. Physicochemical microprocesses engaged in the two earliest phases of the mechanism, the precursor and the incubation phases, are rather specific for each of these materials. In the latter, the slow growth phase, the crack development process passes into a sequence of repeating steps where the specific key microprocesses persist.
\end{abstract}

Keywords: environmentally assisted cracking; initiation; high-temperature water; austenitic stainless steels; carbon steels; low-alloy steels; nickel-based alloys

\section{Introduction}

Environmentally assisted cracking (EAC) is a significant degradation process for components of high-temperature (HT) water-cooled power systems [1,2]. In general, EAC appears under the simultaneous influence of environment and tensile loading on materials. If the load applied is predominantly static, the process is also known as stress corrosion cracking (SCC).

In the light-water-cooled nuclear reactor (LWR) systems, high-temperature (HT) water continuously flows along the surface of components and it can-after long-term operationcreate suitable conditions for EAC initiation. It is well known what basic physicochemical processes take place. Corrosion reaction is in progress on the component surfaces, while protective oxide scales are building up and, at the same time, there takes place a diffusion of the oxide-building chemical elements from within towards the material surface, and diffusion of hydrogen atoms from the water into the material. When load has a suitable level that induces very slow plastic straining, a crack can initiate and grow.

Many studies and material analyses have been performed in the last decades with the aim to understand the EAC mechanism in LWR systems [3-9], although some processes, especially crack initiation, need further understanding. Crack initiation is the longest stage of the degradation process and thus the most important regarding a component's lifetime. This process is the least explored and is not clearly defined. From an engineering point of view, crack initiation is considered to occur when the crack is detectable by non-destructive examination, where detection limits can be several millimeters. This is called "practical" crack initiation. In contrast, with current microscopy techniques, it is possible to investigate submicron-sized cracks and those also considered as crack initiation. This is then called "physical" crack initiation.

This paper reviews the current knowledge about EAC initiation mechanisms occurring in three types of structure materials, namely ferritic low-alloy (LAS) and carbon (CS) steels, austenitic stainless (AS) steels, and Ni-based alloys, which are typical structure materials of LWR system components. For each of the materials, characteristics of the corrosion systems 
and key observations of the EAC process are briefly described. Then, the "physical" crack initiation microprocesses are outlined, through which EAC develops from a solid surface of the original as-machined components up to a penetration into several micrometers. From a general point of view, many commonalities can be found in cracking mechanisms of the three materials, such as the process of surface oxidation, the diffusion of impurities and hydrogen, or the slow crack extension in microscopic steps. However, in detail view, the different chemical compositions, microstructures, and mechanical properties of the three materials begin to play a role and differences can be recognized in the cracking mechanism. Consequently, the cracking appears to have some specific features for each of the materials. Similarities and specifics of these microprocesses are shown as they appear in the selected materials. This article does not aim to describe complete mechanisms, but rather searches for the basic elements of the mechanisms among known experimental data.

\section{Materials}

This paper addresses EAC initiation in only three types of typical structure materials used in current LWR components, excluding the fuel components.

\subsection{Low-Alloy and Carbon Steels}

Low-alloy ferritic-bainitic steels (LAS) are structure materials of LWR reactor pressure vessels, e.g., 20MnMoNi5-5 (1.25wt.\%Mn-0.5Mo-0.3Ni-0.17Cr), equivalent to ASME SA 508 Grade $3 \mathrm{Cl}$. 1 or $22 \mathrm{NiMoCr} 3-7$ (0.70Ni-0.69Mn-0.56Mo-0.33Cr-0.22Si-0.16C), equivalent to SA 533 Grade B Cl. 1, and Russian types 15Ch2MFAA, i.e., CrMoV (2.2Cr-0.55Mo-0.45Mn-0.32Si$0.3 \mathrm{~V}-0.15 \mathrm{Ni})$ and 15Ch2NMFAA, i.e., CrNiMoV (2.2Cr-1.3Ni-0.6Mo-0.5Mn-0.28Si-0.1V).

Carbon steels (CS), e.g., ASTM A106 (0.62Mn-0.19Si-0.19C) and SA 333 Grade 6 (0.30Mn-0.30C), have applications in CANDU systems and in piping and components of secondary circuits of pressurized water reactors (PWRs).

\subsection{Austenitic Stainless Steels}

Austenitic stainless (AS) steels of the 300 series (Fe-10Ni-18Cr-0.05C), types A304, A304L, A316, A316L, A321, A347 (stabilized with Nb), and Russian type 18Cr-10(-12)Ni$\mathrm{Ti}$ (stabilized with $\mathrm{Ti}$ ), are used to build primary and secondary circuit piping, reactor vessel internals (RVI), steam generator tubes and supports, nozzles, and other small items of LWRs.

\subsection{Ni-Based Alloys}

Nickel-based alloys, e.g., the Alloy 600 ( 72Ni-16Cr-9Fe), Alloy 690 ( 60Ni-29Cr-10Fe), Alloy 800 ( 35Ni-23Cr-40Fe), and the corresponding weld metals for dissimilar weldments, e.g., 52/152 ( 60Ni-30Cr-9Fe) and 82/182 ( 66Ni-15Cr-7Fe), are used in reactor pressure vessel nozzles, steam generators tubes, and control rod drive mechanisms of PWRs. The Alloy X-750 ( 70Ni-16Cr-7Fe) is used for small items, such as couplings and springs.

\section{High-Temperature Water Environment}

During LWR long-term operation, the components are exposed to a reducing or slightly oxidizing water environment depending on the reactor type. The water environment determines the character of the protective oxide layer, which plays a key role in EAC crack initiation.

\subsection{Oxidizing Environment}

The coolant of boiling water reactors (BWR) is demineralized water of a temperature usually maintained at $288^{\circ} \mathrm{C}$, low conductivity $(<1 \mu \mathrm{S} / \mathrm{cm})$, and normal water chemistry with about 150-400 ppb of dissolved oxygen, low sulphates and chlorides, with a corrosion potential (ECP) of $\sim 50 \mathrm{mV}_{\mathrm{SHE}}$. Inside the reactor vessel, under the influence of radiation radiolysis, the water dissociates into various molecular, ionic, and radical reaction products that interact to form $\mathrm{H}_{2} \mathrm{O}_{2}, \mathrm{H}_{2}$, and $\mathrm{O}_{2}$ (of those, $\mathrm{H}_{2} \mathrm{O}_{2}$ concentration is about $200 \mathrm{ppb}$ ). 
These compounds increase the ECP, yet the addition of $\mathrm{H}_{2}$ to the reactor water (i.e., hydrogen water chemistry) greatly reduces the effect of radiolysis by scavenging the radiolysis products. For example, the presence of about $500 \mathrm{ppb} \mathrm{H}_{2}(5.6 \mathrm{cc} / \mathrm{kg})$ (the gas dosage is given in $\mathrm{cc} / \mathrm{kg}$, which is an abbreviation of $\mathrm{cm}^{3}(\mathrm{STP}) / \mathrm{kg} \mathrm{H}_{2} \mathrm{O}$, where STP stands for standard temperature and pressure) in water can suppress the effect of radiolysis on the ECP in BWRs [10].

\subsection{Reducing Environment}

PWR primary cooling circuits operate at 260-360 ${ }^{\circ} \mathrm{C}$. The PWR pressurized water, with conductivity of $\sim 20 \mu \mathrm{S} / \mathrm{cm}$, typically contains less than $10 \mathrm{ppb}$ of dissolved oxygen, $\sim 2$ ppm $\mathrm{H}_{2}$ (25-35 cc/kg), low sulphates and chlorides, in addition to 0-1500 ppm B, 1-3 ppm Li and an ECP of -800 $\mathrm{mV}_{\mathrm{SHE}}$. The water of Russian LWR variants (VVER) contains $\mathrm{KOH}(\sim 20 \mathrm{~g} / \mathrm{L})$ instead of LiOH. A hydrogen partial pressure of $\sim 0.17$ to $0.65 \mathrm{bar}$ is maintained above the subcooled primary water at $\sim 150$ bars and 280 to $325^{\circ} \mathrm{C}$ in order to suppress the radiolytic decomposition of water, which has the effect of localizing redox and corrosion potentials of most structural alloys close to the redox potential of the $\mathrm{Ni} / \mathrm{NiO}$ equilibrium [11].

\section{EAC Initiation: Understanding the Mechanism}

The EAC process begins with crack initiation on the component surface and continues with the crack propagation or growth deeper into the material. Kinetics of the two stages of the crack development are very different as shown schematically in the crack depth-time scheme in Figure 1. Very slow process in the initiation stage proceeds into faster process in the propagation stage. No abrupt change of the EAC mechanism at the passage between the two stages has been observed [12].

The crack propagation mechanism is better understood than the crack initiation mechanism. The EAC propagation generally proceeds in repeated steps as follows from many observations of fracture surfaces and crack paths in the microstructure [13-19]. Each of these crack extension steps is induced by a repeated sequence of several physicochemical microprocesses. The size of the crack extension and the duration of these steps determine the velocity of the EAC crack propagation. For example, the EAC crack observed in austenitic stainless steels exposed to hydrogenated primary PWR water is propagated in the step-repeating sequence of the three following microprocesses: (i) enhanced stress concentration in front of the crack tip induced by strain localization; (ii) enhanced oxidation along the dislocation network in the strain localization region; and (iii) local crack extension step at the oxidized region in front of the crack tip [12].

According to Staehle [20], who first established the crack depth-time scheme shown in Figure 1, three phases can be distinguished in the EAC crack initiation mechanism, i.e., the precursor, the incubation, and the slow growth. The precursor phase, setting necessary conditions for the crack initiation to occur, involves processes occurring on the surface without any penetration under it, such as accumulation of deposits on superheated surfaces, lead accumulation, depletion of alloy species, surface wear, or grain boundary (GB) oxidation. The slow development of conditions necessary for the crack typically makes precursor the longest initiation mechanism phase. The stress does not need to be applied during the whole precursor phase. During the incubation phase, the crack growth starts but with a negligible penetration, due to processes like intergranular penetration, change in oxide scale composition, or local creep. The slow growth phase characterizes a period when the crack starts to grow, but with a much slower rate than in the next propagation stage. The crack development passes from initiation into propagation when the crack depth is about 50-500 $\mu \mathrm{m}$. Such a crack represents the onset of crack growth at engineering relevant rates [21]. This is already the "practical" initiation, even if the crack is detectable only with a special non-destructive examination technique. 


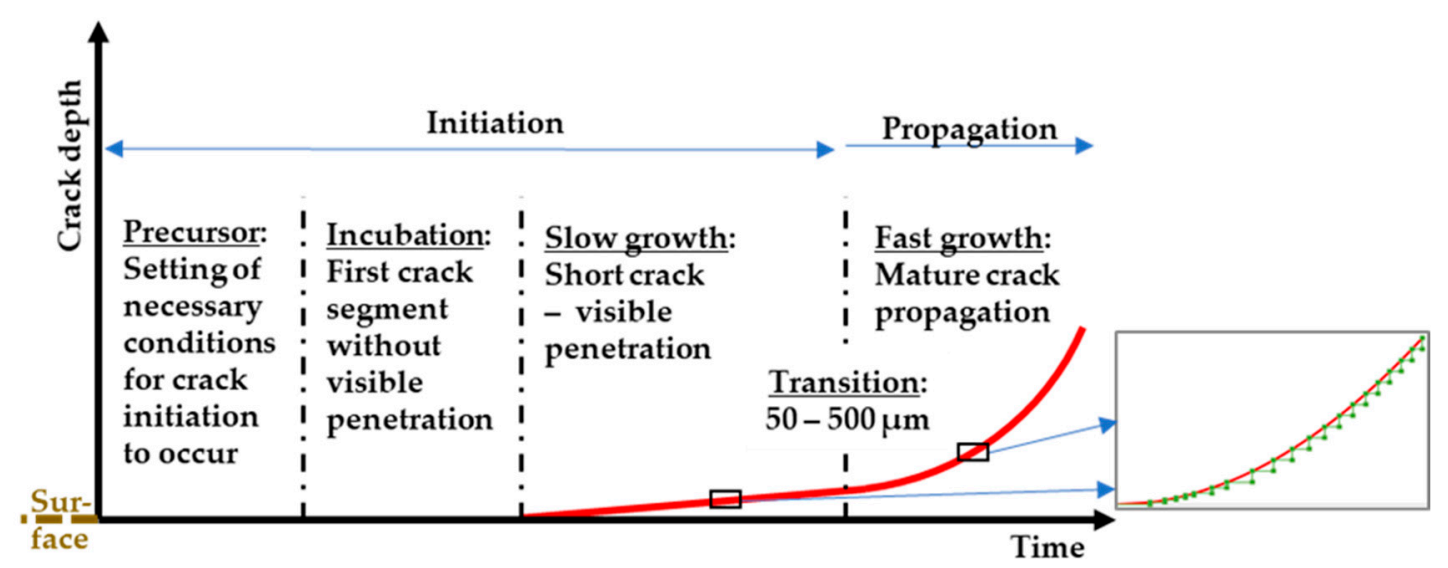

Figure 1. Scheme of environmentally assisted cracking (EAC) crack development from surface showing definition of the initiation, including the precursor, the incubation, and the slow growth, and the propagation stages; adapted based on Staehle [20].

In the slow or fast growth phases of the crack development, the physicochemical character of each microprocess can be considered similar and not dependent on the cracking stage. It can be expected that physicochemical processes occurring during the slow growth are likely repeated but accelerated in the propagation stage. In contrast, the physicochemical processes of the precursor and incubation phases can be different as at least their kinetics are much slower. Therefore, the precursor and the incubation phases should be studied separately. It is likely that the microprocesses in these two phases depend on structure materials and the corresponding high-temperature water systems. An investigation of the microprocesses in these two phases is given in the following sections.

\subsection{Low-Alloy and Carbon Steels}

\subsubsection{Brief Characteristics of the Corrosion System}

The chemical interaction of low-alloy (LAS) and carbon (CS) steels with HT water results in oxidation of the surfaces; a thick oxide scale builds up obeying the parabolic law $\left(\Delta \mathrm{x}^{2} \sim \mathrm{t}\right)$. Typically, a double-layer oxide develops, with the inner layer compact and the outer layer formed of crystallite particles of magnetite $\left(\mathrm{Fe}_{3} \mathrm{O}_{4}\right)$. It is worth noting that the oxide scales develop on the surface of CS components in CANDU systems and the surface of LAS specimens exposed to the LWR primary water simulated in labs. The oxide scales do not develop in the LWR primary circuits where the LAS components are purposely protected by stainless steel cladding [22]. As the hydrogen has high diffusivity in the steels at temperatures around $300{ }^{\circ} \mathrm{C}$, the hydrogen atoms produced at this corrosion reaction penetrate deep into the metal and concentrate in structural traps, such as dislocations, vacancies and other lattice defects, and in stress concentration sites.

The typical microstructure of LAS materials consists of several bainite packets (ferritic phase) arranged inside original austenite grain boundaries. In contrast, the microstructure of the CS materials is a mixture of ferrite/ferrite and ferrite/pearlite structures, where carbides $\left(\mathrm{Fe}_{3} \mathrm{C}\right)$ mainly precipitate at ferrite/pearlite boundaries [23].

These steels have relatively high strength ( $650 \mathrm{MPa})$ and low ductility, which excludes high strain localization. The dynamic strain aging (DSA) effect can occur in the steels when slow loaded at temperatures around $300{ }^{\circ} \mathrm{C}$. This effect, caused by an interaction between moving dislocations and interstitials, makes the steels appear to be stronger and harder when slow loaded. Creep does not occur at these temperatures $\left(\sim 0.3 \mathrm{~T}_{\mathrm{M}}\right)$. The concentration of thermal equilibrium vacancies is estimated to be $\sim 10^{-7}$ at around $300{ }^{\circ} \mathrm{C}$ (based on data for pure $\mathrm{Fe}$ or $\mathrm{Cr}$ metals), which is ten times lower than a limit concentration $\left(\sim 10^{-6}\right)$ enabling intergranular creep [23]. By cold working (CW), the number of thermal vacancies is increased and those persist in the material for a long time even at these temperatures [23]. 


\subsubsection{Description of EAC in the Corrosion System}

As it has been recognized, EAC initiation does not occur easily and EAC does not sustainably propagate in the LAS and CS materials in the HT water environments subjected to constant loadings in the elastic regime [22,24-27]. EAC initiation from smooth, defectfree surfaces subjected to a static load is generally observed only for stresses above the HT yield strength, quasi-stagnant water flow conditions, and increased concentration levels of anionic impurities, such as $\mathrm{SO}_{4}{ }^{2-}$ or $\mathrm{Cl}^{-}$[24]. The crack path under these conditions is usually transgranular (TG) $[24,26]$. EAC in elastoplastic load conditions is termed straininduced corrosion cracking (SICC) [24,26]. In simulated HT water containing oxygen, EAC initiates more easily and transgranular cleavage-like crack growth is mostly observed (Figure 2a,b). Sporadically, the intergranular (IG) fracture in local islands is found, e.g., in lab testing of $\mathrm{CrMoV}$ and $\mathrm{CrNiMoV}$ steels in oxygenated HT water [27].

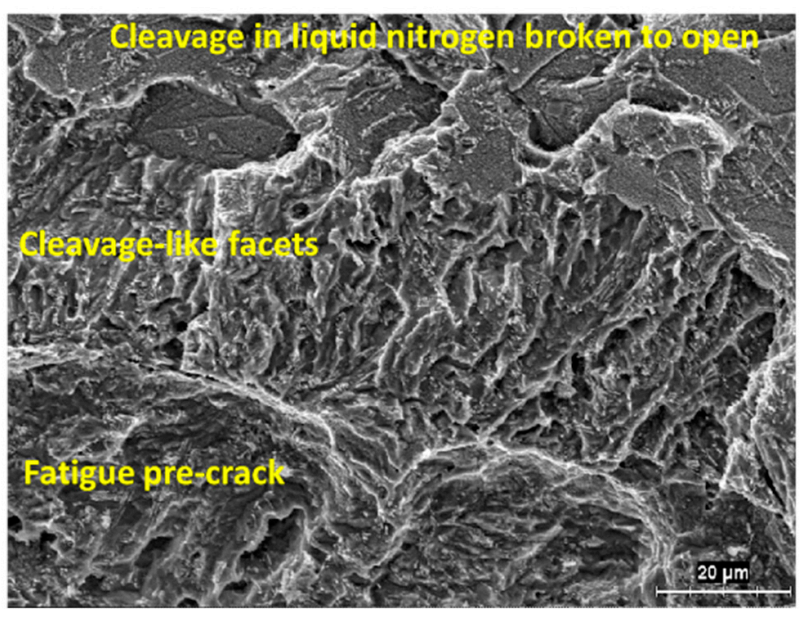

(a)

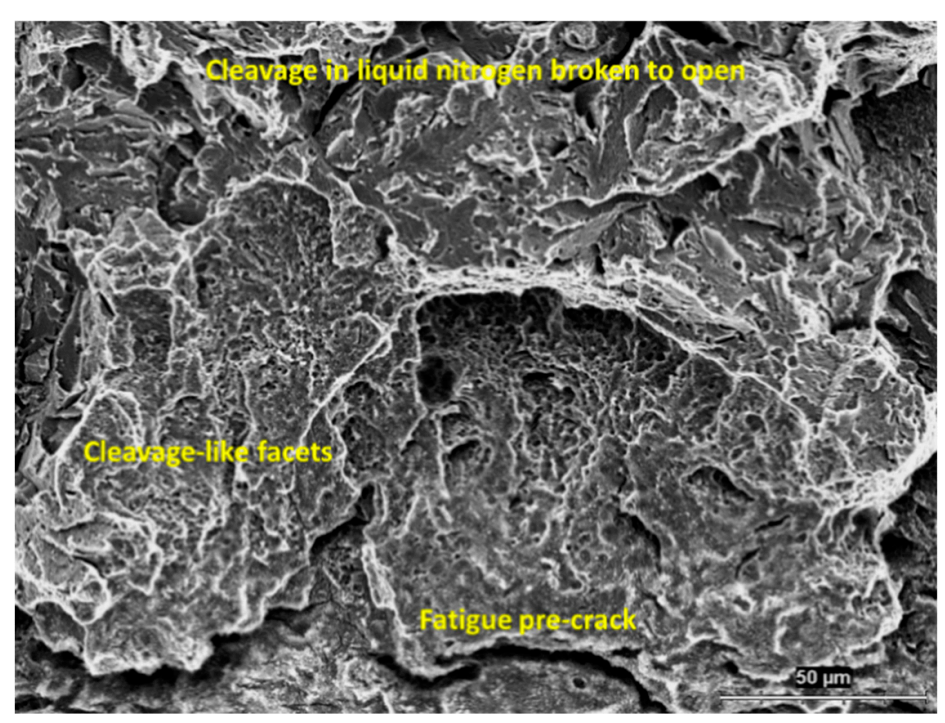

(b)

Figure 2. Typical cleavage-like facets of EAC initiated in low-alloy steels (LAS) growing from fa-tigue pre-crack tip while tested by constant load: (a) 22NiMoCr3-7 exposed to simulated boiling water reactor (BWR) conditions at $288^{\circ} \mathrm{C}$ for $1904 \mathrm{~h}$ at stress intensity of $49 \mathrm{MPam} 1 / 2$; (b) CrNiMoV exposed to simulated VVER water saturated with oxygen $(>1 \mathrm{ppm})$ at $320{ }^{\circ} \mathrm{C}$ for $1023 \mathrm{~h}$ at $36 \mathrm{MPam}^{1 / 2}$. The fracture surfaces were chemically cleaned to remove oxides.

A recent investigation of EAC initiation in CW CS after more than $5000 \mathrm{~h}$ under constant load in HT water or in air has revealed fine cavities at phase boundaries under surface developed before a crack initiation [28]. Particularly in 30\% CW CS notched specimens exposed to the stress intensity of $35 \mathrm{MPam}^{1 / 2}$ for $8082 \mathrm{~h}$ in $360{ }^{\circ} \mathrm{C}$, the fine cavities appear in the high-stress concentration region in front of the specimen notch root, i.e., in the elastoplastic loading region, both in water and in air [29,30]. It suggests that creep occurs in the CW steels at the test condition. In addition, it appears that the number of cavities in front of the notch increases with time of exposure and that the rate of cavity formation in the water is more than ten times higher than in air. It suggests that the diffusion of vacancies that form the cavities and the consequent creep are enhanced in water [28]. This enhancement can be likely explained by the presence of hydrogen atoms in the vacancies because the concentration of hydrogen is measured to be higher close to the fracture than in other locations [28-30]. Indeed, atomistic simulations [31] have revealed that vacancy-hydrogen complexes $\left(\mathrm{V}_{\mathrm{n}} \mathrm{H}_{\mathrm{m}}\right)$ can be produced in bcc $\alpha$-Fe in high concentrations $\left(\sim 10^{-3}-10^{-5}\right)$, if the steel is $\mathrm{CW}$. The $\mathrm{V}_{\mathrm{n}} \mathrm{H}_{\mathrm{m}}$ can remain metastable for a rather long time and develop into cavities, while absorbing additional vacancies. 


\subsubsection{EAC Initiation Mechanism}

EAC initiation can occur in LAS and CS steels while simultaneously exposed to the elastoplastic loading and HT water. These conditions facilitate oxide scale failures and thus increase entry of $\mathrm{H}$ atoms, and also stimulate local plastic deformation, i.e., formation and motion of dislocations.

Since EAC of the LAS shows mostly cleavage-like transgranular crack paths, the microprocesses occurring inside grains should be considered dominant in the crack initiation mechanism. In addition, the non-sustainability of the EAC growth has to also be considered. After initiation, the crack grows only inside a single grain; to allow continuation of growth over this barrier a reinitiation may be needed.

An excess of hydrogen likely assists dissipation of strain inside grains. It is known that $\mathrm{H}$ atoms attracted into dislocation cores facilitate the motion of dislocations and thus enable their higher densities in pile-ups [32]. Moreover, atomistic modelling has shown that dislocations are attracted to the $\mathrm{V}_{\mathrm{n}} \mathrm{H}_{\mathrm{m}}$ complexes and then pinned by them [33]. The crack embryo can form in the hardened and enhanced plasticity regions developed from these pile-ups, as it has been proposed in the corrosion-enhanced plasticity model [34]. In contrast, EAC initiation in the CS steels occurs along ferrite/pearlite boundaries with an assistance of creep stimulated by hydrogen [30].

In agreement with all these findings, the following summary of the two earliest phases of the EAC initiation process in LAS and CS steels can be drawn.

(i) In the precursor phase: An oxidation occurs on the surface together with outward diffusion of atoms constituting the metal and inward diffusion of $\mathrm{H}$ atoms. The $\mathrm{H}$ atoms penetrate into dislocations and bond with vacancies to form $\mathrm{V}_{\mathrm{n}} \mathrm{H}_{\mathrm{m}}$ complexes, which diffuse towards structure boundaries or other interfaces and form fine cavities.

(ii) In the incubation phase: The cavities grow and coalesce to a critical size, in particular in the sub-surface region where irregularities activate concentration of stress; in parallel, dislocations move along slip planes in the sub-surface region. The first penetration into the metal occurs when the first pile-ups or cavities allow the new dislocation emissions to form a wedge microcrack.

\subsection{Austenitic Stainless Steels}

\subsubsection{Brief Characteristics of the Corrosion System}

The AS steels are corrosion resistant due to their high chromium and nickel contents. Their chemical interaction with the HT water environment results in thin slow-growing oxide scales protecting the surface. For example, a microscopic investigation of the surface of a Type 316L pressurizer heater after its service in a PWR primary cooling circuit $\left(360^{\circ} \mathrm{C}\right.$ for $115,000 \mathrm{~h}$ ) revealed a double-oxide scale containing the $\mathrm{Cr}$-rich internal oxide layer

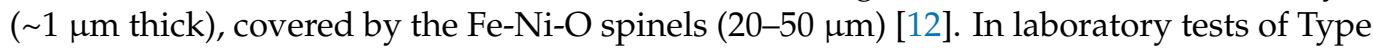
316 steel, a thin duplex oxide layer was reported to develop under stress in simulated PWR nominal water for $500 \mathrm{~h}$, consisting of a compact inner layer composed of $500 \mathrm{~nm}$ thick $\mathrm{FeCr}_{2} \mathrm{O}_{4}$ spinels and a coarse-grained outer layer of $\mathrm{Fe}_{3} \mathrm{O}_{4}$ spinel crystals of 1-2 $\mu \mathrm{m}$ diameter [35]. A double-layer oxide film, with an Fe-rich outer layer and fine-particle Cr-rich inner layer, has been observed in Type 316L steel exposed to the simulated PWR water at $320{ }^{\circ} \mathrm{C}$; both layers consisted of spinels $(\mathrm{FeCrNi})_{3} \mathrm{O}_{4}$ and there was no change in the oxide film structure with a concentration of the dissolved hydrogen ranging from 1 to $45 \mathrm{cc} / \mathrm{kg} \mathrm{H}_{2}$ [36]. Similar results were obtained for Type 304 steel, e.g., at $360{ }^{\circ} \mathrm{C}$ [37]. It is worth noting that a surface treatment and corresponding subsurface deformation significantly affects development of the oxide scale, as well as $\mathrm{Cr}$ and $\mathrm{Ni}$ diffusion $[7,38,39]$. Local intergranular or slip band oxidations were observed [38,40], e.g., up to $1.4 \mu \mathrm{m}$ in depth from a polished surface of a 20\% cold-rolled Type 316L steel sample exposed to PWR water at $290^{\circ} \mathrm{C}$ for $1000 \mathrm{~h} \mathrm{[38].}$

Diffusivity of hydrogen in AS steels in the solution-annealed state is very low at temperatures around $300{ }^{\circ} \mathrm{C}$, but it is significantly increased by a cold work. For example, $20 \%$ CW 316 steel showed the diffusivity increased about 5000 times in comparison to 
the annealed steel at $360{ }^{\circ} \mathrm{C}$ [23], and this diffusivity was further accelerated with the application of tensile stresses [39]. At higher temperatures with hydrogen gas at $600{ }^{\circ} \mathrm{C}$, creep testing of Type 304 steel showed that the penetrating hydrogen accelerates dislocation creep [41].

AS steels typically have a medium strength and high ductility, but both these characteristics may considerably vary with heat treatment and cold work. These steels respond strongly to mechanical loading with complex strain paths, which could result in local high strain localizations close to the grain boundaries and other interfaces. In addition, slow straining at the LWR temperatures stimulates the DSA effect in these steels.

\subsubsection{Description of EAC in the Corrosion System}

AS steels are very resistant to EAC in typical PWR and BWR conditions, characterized by the components exposed to HT water with a controlled chemical regime and their loading limited to elastic. However, EAC initiation can be stimulated in AS steels by a cold work above $10 \%$, by harsh surface treatments [6-9], or by increased levels of $\mathrm{SO}_{4}{ }^{2-}$ or $\mathrm{Cl}^{-}$concentration. EAC has been observed as a root cause of some component damage in service $[1,2,12]$. EAC initiation has also been emulated in autoclave testing in HT water [6-9,42-46]; examples are shown in Figures 3 and 4. Both intergranular and transgranular EAC are observed, while the IG mode dominates cracking cases in service conditions and/or in long-term constant load testing in simulated lab conditions [12,43,44], and the TG mode is more often observed in testing accelerated by slow strain rates $[12,45]$.

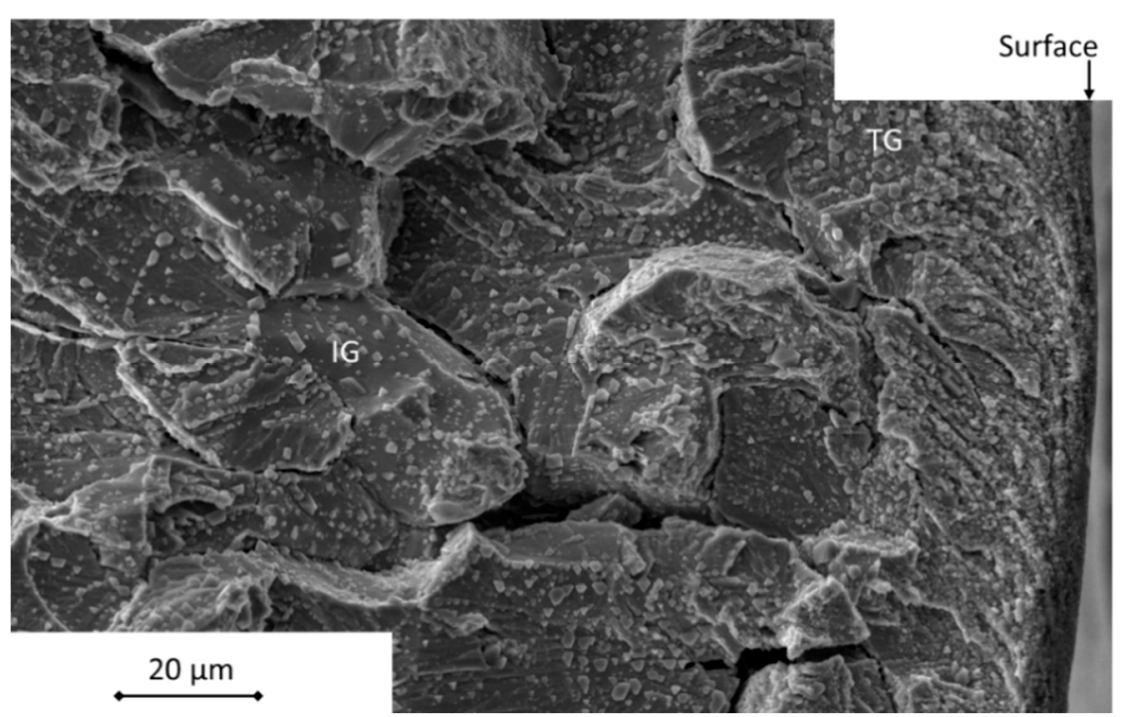

Figure 3. Fracture surface of $08 \mathrm{Ch} 18 \mathrm{~N} 10 \mathrm{~T}$ AS steel after accelerated EAC testing (strain rate of $1 \times 10^{-7} \mathrm{~s}^{-1}$ at the tension loading up to rupture) in $\mathrm{HT}$ water $\left(320^{\circ} \mathrm{C}, \mathrm{KOH},<20 \mathrm{ppb} \mathrm{O}_{2}\right.$, without $\mathrm{H}_{2}$ gas addition) showing the path of the crack from its initiation in the surface layer (deformed by harsh turning), where it had TG and cleavage-like character, to its propagation into depth, where the path was locally IG. 

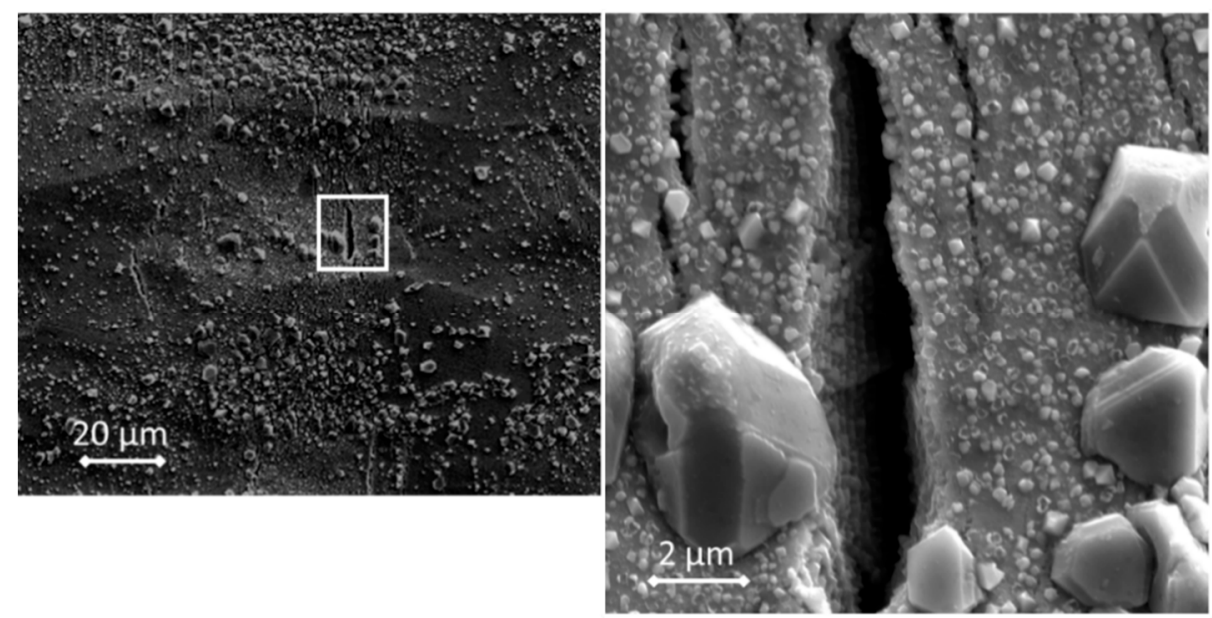

(a)

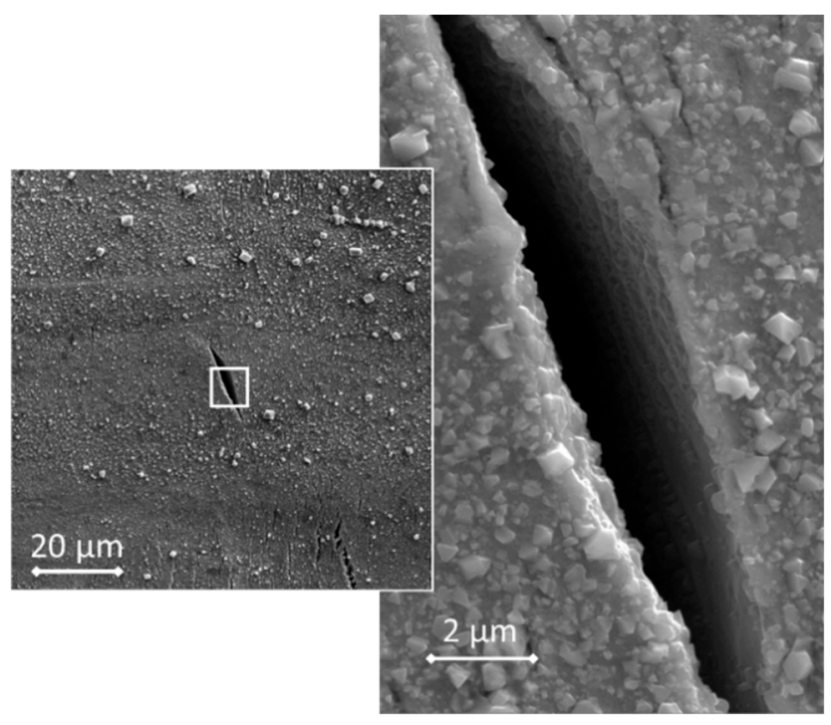

(b)

Figure 4. Example of EAC initiation on the surface of solution-annealed Type 316L steel strained (of $1 \times 10^{-6} \mathrm{~s}^{-1}$ in tension in horizontal direction) in $\mathrm{HT}$ water $\left(350^{\circ} \mathrm{C}, \mathrm{LiOH},<20 \mathrm{ppb} \mathrm{O}_{2}\right.$, without $\mathrm{H}_{2}$ addition) [45]. The images show deformation bands, oxide particles, and cracks on the surface, together with zoomed views of boxed area of the following cracks: (a) TG cleavage-like (at local plastic strain of 0.12) and (b) IG (at 0.10). Note the fine steps lined with fine oxide particles on the internal surfaces of opened cracks.

EAC initiation has been investigated in many microstructure studies e.g., $[12,38,43,44]$. The IG crack initiation is found as consequence of localized deformation and debonding at grain boundaries [12]. To determine local conditions of the initiation, $11 \% \mathrm{CW}$ Type $316 \mathrm{~L}$ steel was studied slow loaded up to $4 \%$ strain in simulated PWR water at $340{ }^{\circ} \mathrm{C}$ [44]. For those conditions, mechanical fields inside grains and grain boundaries (GB) on the surface of the specimens have been investigated experimentally and modelled. The results showed that the majority of the GBs, which cracked in the test conditions, were high-angled (HAGB), perpendicular to the tensile axis, and at the points of maximal normal stress and plastic strain. However, not all the GBs withstanding these stresses and strains developed cracks, and some GBs failed while the normal stress applied on them was lower than the maximal stress. It suggests that mechanical loading itself is not a sufficient criterion for EAC initiation. Other factors, such as intergranular oxidation depth, have to be included in the initiation mechanism. 


\subsubsection{EAC Initiation Mechanism}

The key elements of EAC initiation of AS steels are known to be local intergranular oxidation and localized plastic strain. Nevertheless, both IG and TG cracks may initiate in the same material and water, irrespective of grain boundary segregations or other weakening, and depending only on the applied strain rate. It suggests that the plastic strain rate is another key element of the EAC mechanism.

The local model [47], developed for EAC degradation prediction, assumes crack initiation being possible at a grain boundary once the following cracking criteria are reached: intergranular oxidation deeper than the critical oxidation depth (130-200 nm) and intergranular stress higher than the critical intergranular stress (500-2000 MPa). The third key factor, namely the plastic deformation, is thus included indirectly. This factor manifests itself at the fined-element model mesh as a strain induced by applied stress, but it is not yet considered among cracking criteria.

In agreement with all these findings, the following summary of the two earliest phases of the EAC initiation process in the AS steels can be drawn:

(i) In the precursor phase: An oxidation occurs on the surface together with outward diffusion of atoms constituting the metal and inward diffusion of $\mathrm{H}$ atoms affected by applied stress and local plastic straining; oxidation enters the grain boundaries and slip bands underneath the surface.

(ii) In the incubation phase: Oxidation of the grain boundaries and slip bands goes deeper under the surface. When both the critical oxidation depth and critical localized strain are reached, the first penetration into the metal occurs in and along the grain boundary in the case of IG cracking, or in the cleavage plane containing the slip band in the case of TG cracking.

\subsection{Ni-Based Alloys}

\subsubsection{Brief Characteristics of the Corrosion System}

Nickel-based alloys are very resistant to corrosion in the HT water environment and form only very thin oxide films on the surface. For example, a Cr-rich oxide layer $(\sim 90 \mathrm{~nm})$ with a Cr-depleted underlayer $(\sim 0 \mathrm{~nm})$ has been found in Alloy 600 (mechanically polished down to $1 \mu \mathrm{m}$ ) exposed to simulated PWR water at $360^{\circ} \mathrm{C}$ for $300 \mathrm{~h}[11,48]$. In the case of Alloy 690 with an electropolished surface exposed to water with $18 \mathrm{cc} / \mathrm{kg} \mathrm{H}_{2}$ (NiO regime) at $360{ }^{\circ} \mathrm{C}$ for $\sim 1300 \mathrm{~h}$, it developed a penetrative inner oxide film, about $100 \mathrm{~nm}$ thick, composed of $\mathrm{Cr}$-rich $(\mathrm{Fe}, \mathrm{Cr}, \mathrm{Ni})_{3} \mathrm{O}_{4}$ and $\mathrm{Cr}_{2} \mathrm{O}_{3}$ oxides, with outer $\mathrm{NiFe}_{2} \mathrm{O}_{4}$ particles [49].

The nature and thickness of the formed oxide films depend on dissolved $\mathrm{O}_{2}$ and $\mathrm{H}_{2}$ contents. In Alloy 600 exposed to water at $288{ }^{\circ} \mathrm{C}$, the nature of the oxide film differs according to the concentration of hydrogen dissolved in water: at 5-10 $\mathrm{ppb} \mathrm{H}_{2}$, the oxide film is double-layered and compact, under levels of $150-600 \mathrm{ppb} \mathrm{H}_{2}$ (i.e., around the $\mathrm{Ni} / \mathrm{NiO}$ transition), it is double-layered but contains many defects, and at $1200 \mathrm{ppb} \mathrm{H}_{2}$ (where no Ni oxidation is expected), it is single-layered, ultra-thin, and $\mathrm{Cr}$-enriched [50]. In Alloy 600 exposed to simulated PWR water at $325^{\circ} \mathrm{C}$ without stress, the proportion of critically oxidized GBs was the highest for the dissolved $\mathrm{H}_{2}$ concentration of $43 \mathrm{cc} / \mathrm{kg}$ (close to the $\mathrm{NiO} / \mathrm{Ni}$ transition) and growing with time; this proportion decreased for concentrations of 1.5 and $945 \mathrm{cc} / \mathrm{kg}$ [51]. In the case of Alloy 182 exposed to simulated PWR water at $325{ }^{\circ} \mathrm{C}, \mathrm{NiO}$ formed on the surface at $5 \mathrm{cc} / \mathrm{kg} \mathrm{H}_{2}$, whereas $\mathrm{Cr}_{2} \mathrm{O}_{3}$ and $\mathrm{NiFe}_{2} \mathrm{O}_{4} / \mathrm{NiCr}_{2} \mathrm{O}_{4}$ spinel oxides appeared at 25 and $50 \mathrm{cc} / \mathrm{kg} \mathrm{H}_{2}$ [52].

In addition, preferential intergranular oxidation (PIO) has been discovered, for example, in Alloy 600 exposed to simulated PWR water [53-55]. The PIO particularly means that emerged-to-surface grain boundaries locally oxidize and therefore they also locally migrate. Figure 5 shows an example of PIO in Alloy 600 after its long-term exposure to water (in Ni stability conditions) with no externally applied stress [53]. 


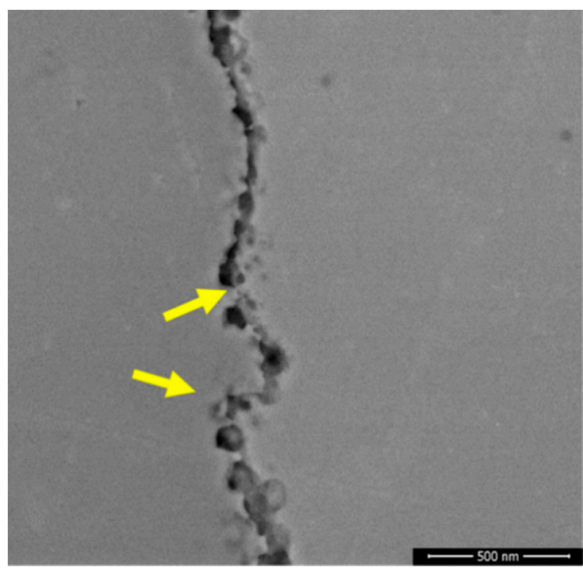

(a)

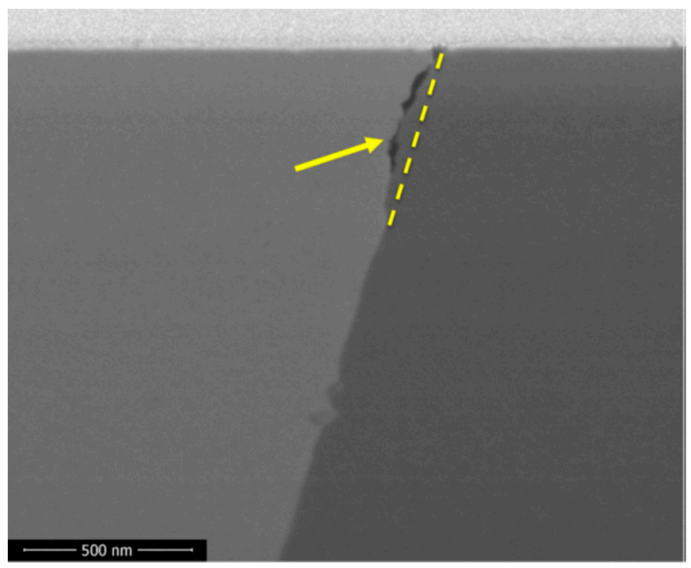

(b)

Figure 5. SEM-BSE images of Alloy 600, originally with polished surface, after its exposure for $1000 \mathrm{~h}$ to simulated PWR water (of $40 \mathrm{cc} / \mathrm{kg} \mathrm{H}_{2}$, i.e., in the Ni stability region, and at $320^{\circ} \mathrm{C}$ ), with no applied stress, showing: (a) GB undulations on the surface (indicated by arrows) and (b) in cross-section a GB oxidation (where the dark imaging penetration, indicated by an arrow, has been confirmed to be $\mathrm{Cr}_{2} \mathrm{O}_{3}$ ) and GB migration (where a dashed line marks the GB original position). Reprinted from the open-access publication [53].

Ni-based alloys have a microstructure consisting of main austenitic phase and secondary phase carbides. In general, the alloys are characterized by a high strength and ductility, especially at high temperatures (up to $\sim 600^{\circ} \mathrm{C}$ ) and a very good creep resistance. It has been found that cold working accelerates Ni diffusivity at the LWR operating temperatures and that the $\mathrm{CW}$-induced vacancies stay in the materials over a long period of time [23]. In comparison to carbon steels, about 10 times fewer cavities take part in the creep of Ni-based alloys at temperatures around $300{ }^{\circ} \mathrm{C}$. A good correlation between the rate of cavity formation and crack growth has been observed for creep. It suggests that intergranular crack growth in gas environments at these temperatures is controlled by the rates of cavity formation in the CW materials [23].

\subsubsection{Description of EAC in the Corrosion System}

Many cracks have been found in Alloy-600 PWR plant components, which were in service up to 25 years [11]. This EAC susceptibility of Alloy 600 was then confirmed in accelerated EAC-initiation testing [21,56]. A typical EAC of Alloy 600 has IG character and initiates from the grain boundary oxidation, as illustrated in Figure 6 [21].

Testing of several Ni-based alloys at various HT water chemistries and temperatures has shown that the EAC crack growth rate shows a maximum near the $\mathrm{Ni} / \mathrm{NiO}$ transition, see Figure 7a [57,58]. Additionally, EAC initiation appears to be a function of the content of dissolved $\mathrm{H}_{2}$ in water and its time depends on the distance of the corrosion potential from the $\mathrm{NiO} / \mathrm{Ni}$ stability transition, see Figure $7 \mathrm{~b}[51,56,58]$. It suggests that hydrogen, which is diffusing more easily into metal not covered with the $\mathrm{NiO}$ oxide, does play a role in the EAC process. Moreover, it appears that the fundamental mechanical parameter controlling EAC initiation is the plastic strain, not stress [56], which suggests that the GB opens to crack rather by shear than by rupture. 

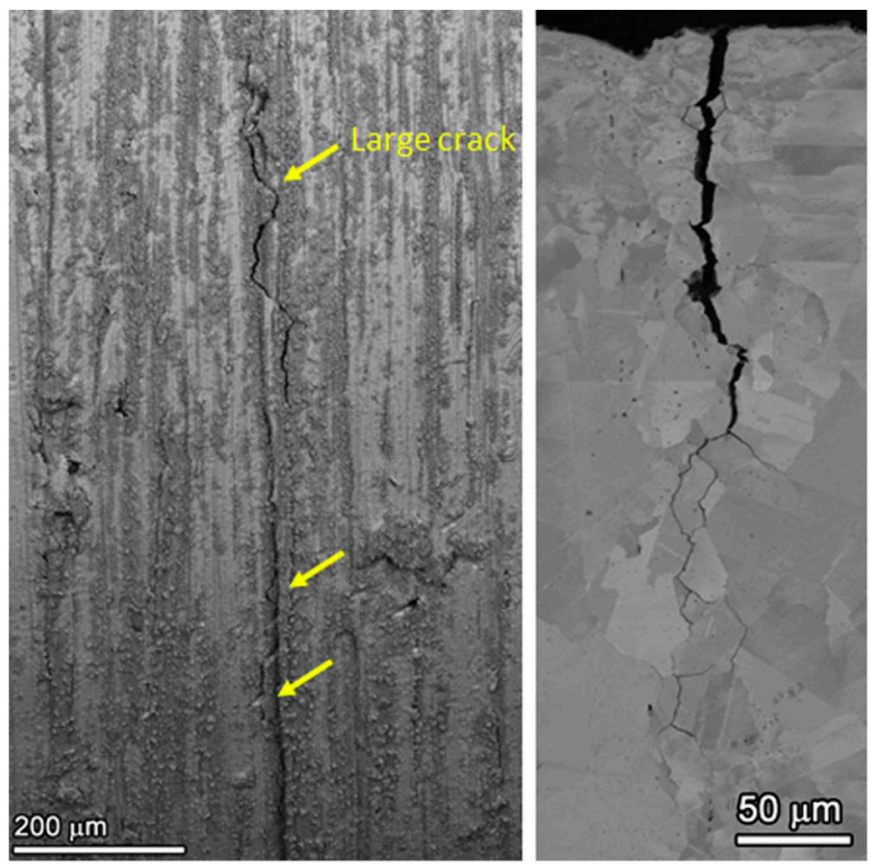

Figure 6. SEM-BSE images of Alloy 600 (as a 60-grit ground finish plate specimen), which has been exposed for $6900 \mathrm{~h}$ to simulated PWR water (in Ni/NiO transition conditions, and at $360^{\circ} \mathrm{C}$ ) and to the load at the yield strength level, showing a typical morphology of a large crack, as seen on the surface and in cross-section, reproduced from [21], with permission from Elsevier, 2020.

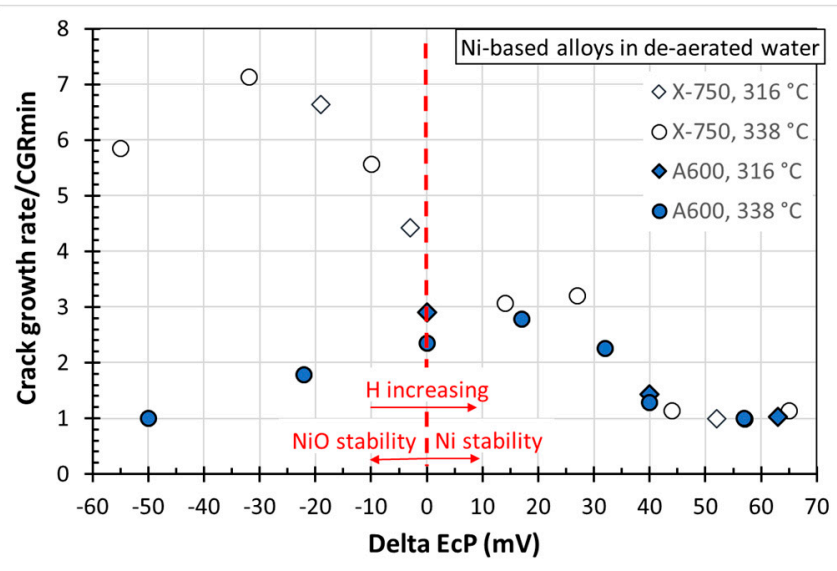

(a)

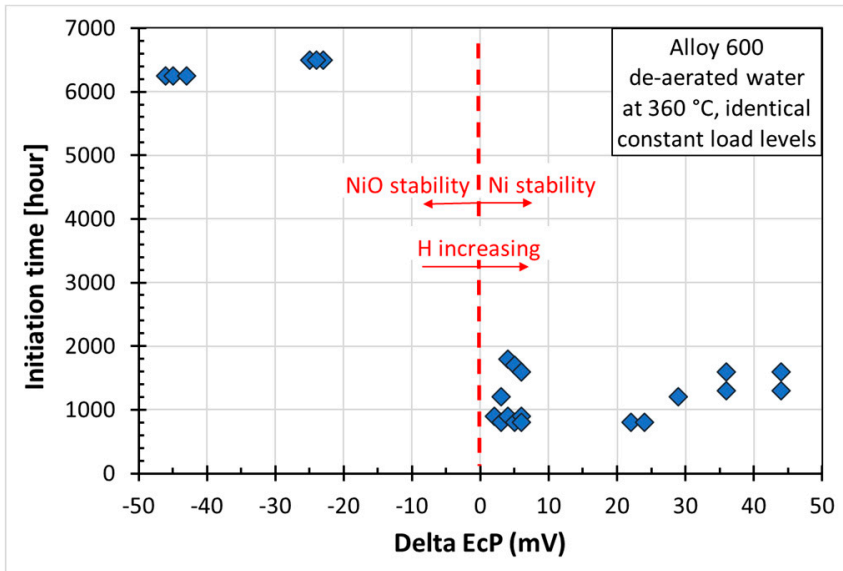

(b)

Figure 7. EAC susceptibility of Ni-based alloys as a function of the content of dissolved $\mathrm{H}_{2}$ in water. (a) Chart of the EAC crack growth rate normalized to a minimum value (CGRmin) of X-750 and $\mathrm{A} 600$ alloys, exposed to de-aerated water at $316{ }^{\circ} \mathrm{C}$ and $338{ }^{\circ} \mathrm{C}$, versus the difference of electrochemical potentials from the $\mathrm{NiO} / \mathrm{Ni}$ transition (Delta $\mathrm{EcP}$ ). The results show that maximum values are found in a distance close to the $\mathrm{Ni} / \mathrm{NiO}$ transition. The chart is based on the published data [57]. (b) Chart of the EAC initiation time of high-temperature-annealed Alloy 600, exposed to de-aerated water at $360{ }^{\circ} \mathrm{C}$ with identical stress applied, versus Delta EcP. The results show that the EAC initiation times are much longer under conditions with stability of the nickel oxide than they are with stability of the nickel metal. The chart is based on published data [56].

In contrast, while Alloy 690 is considered resistant to EAC initiation under operational conditions, recent experimental studies have identified conditions when EAC initiation does occur. During long-term testing of $20 \%$ CW Alloy TT690 (under static load and exposed to hydrogenated water at 320 and $360^{\circ} \mathrm{C}$ for 20,653 to $34,484 \mathrm{~h}$ ), IG crack initiation was found and discovered to occur due to the formation of cavities at GBs. The very fine 
cavities $(\sim 0.1 \mu \mathrm{m})$ were observed on crack surfaces, initiated by creep in air and by EAC in water $[23,59]$. Because the crack growth rate in the water was determined to be ten times higher than in the air, it has been suggested that the rate of cavity formation in Ni-based alloys, exposed to HT water, is also affected by penetrated hydrogen [23,30]; yet, this impact of hydrogen can be expected to be more pronounced for carbon steel.

Another testing of EAC initiation with Alloy 690 exposed to simulated PWR primary water was interrupted at different stages of the initiation process in order to perform microscopical investigation [60-63], see Figure 8. It was found that with increasing time of exposure under load, fine cavities coalesce at GBs under the surface and form a microcrack. Then, the IG crack opens and slightly extends, and its flanks oxidize. Next, the mature crack continues to grow, in a way similar to creep [61]. Other microscopic investigation has shown that, initially, a compact layer of $\mathrm{Cr}_{2} \mathrm{O}_{3}$ forms over a migrated $\mathrm{GB}$ (driven by the diffusion of $\mathrm{Cr}$ ) and small cavities appear on the GB [62]. The further straining then breaks this surface $\mathrm{Cr}_{2} \mathrm{O}_{3}$, oxygen diffuses along the $\mathrm{GB}$, and this results in the formation of a mixture of $\mathrm{NiO}$ and $\mathrm{Cr}_{2} \mathrm{O}_{3}$ oxides. Thus, the crack initiates along the heavily oxidized migration zone of the GB [62].
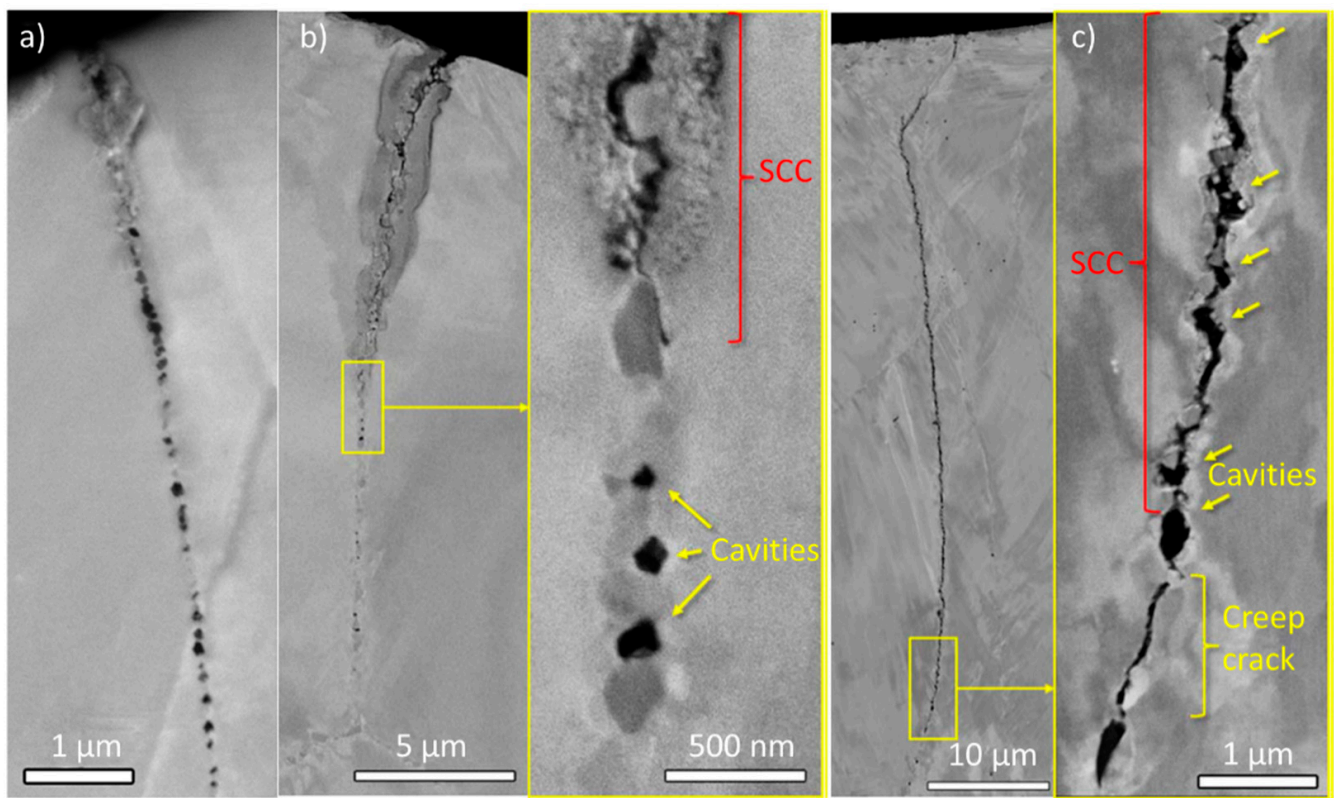

Figure 8. SEM-BSE images of cross-sections of EAC initiation in 21-31\% CW Alloy 690, after testing conducted at $360{ }^{\circ} \mathrm{C}$ in simulated PWR primary water $(600 \mathrm{ppm}$ of $\mathrm{B} ; 1 \mathrm{ppm}$ of $\mathrm{Li} ; 25 \mathrm{cc} / \mathrm{kg}$ dissolved $\mathrm{H}$, i.e., in $\mathrm{Ni} / \mathrm{NiO}$ transition conditions), showing the presence of $\mathrm{GB}$ cavities assisting the cracking. Three examples of the GB cavities are shown: (a) the first penetration at 5,352 $\mathrm{h}$, (b) a shallow IG crack at 10,049 h, and (c) a mature crack at 11,709 $\mathrm{h}$ [61], reproduced from [63], with permission from Elsevier, 2020.

\subsubsection{EAC Initiation Mechanism}

Crack initiation in Ni-based alloys is assisted by creep induced by formation, growth, and coalescence of the GB cavities [60] or by dynamic straining [63].

In agreement with the current findings, the following summary of the two earliest phases of the EAC initiation process in the Ni-based steels can be drawn.

(i) In the precursor phase: An oxidation of the surface inducing the diffusion of metal constituents and $\mathrm{H}$ atoms occurs; development of the outer oxide film depends on dissolved hydrogen content-in the Ni stability regime the spinel oxide forms, which is less protective to $\mathrm{O}$ and $\mathrm{H}$ penetration, while in the $\mathrm{NiO}$ stability regime, the stable $\mathrm{NiO}$ acts as a barrier to diffusion and less $\mathrm{O}$ and $\mathrm{H}$ penetrate the oxide film; then, an inner $\mathrm{Cr}$-rich layer forms locally on the surface over the GBs and this results in PIO and migration of the GBs; $\mathrm{H}$ atoms form complexes with vacancies that diffuse and develop into fine cavities. 
(ii) In the incubation phase: Ongoing surface oxidation depletes of chromium the parts of GBs nearer to the surface; oxygen diffuses into the metal along the GBs and forms oxides, the greatest amount close to the $\mathrm{Ni} / \mathrm{NiO}$ transition; other cavities grow and coalesce on the GBs in the subsurface region, which results in a slide in the GBs causing a rupture of the IG oxide, i.e., the first penetration.

\section{Concluding Remarks}

This review summarizes the current knowledge of EAC initiation in three selected corrosion systems, namely the ferritic low-alloy and carbon steels, austenitic stainless steels, and Ni-based alloys, exposed to high-temperature water and load. It appears that no clear conclusion can be drawn about the conditions under which a crack embryo can emerge in these materials, due to many interrelated and time-dependent factors involved in the process.

The review shows that each of the corrosion systems exhibits its own specific physicochemical microprocesses of the crack initiation mechanism in its two earliest phases. The key microprocesses acting in the precursor and incubation phases are different for each of the corrosion systems. The key microprocesses are specifically as follows: for the ferritic low-alloy and carbon steels, a significant role played by hydrogen on cavity formation and transgranularity and the non-sustained character of the cracking; for the austenitic stainless steels, a local intergranular oxidation and a localized plastic strain and its particular kinetics; for the Ni-based alloys, a surface oxidation affected by the concentration of dissolved hydrogen, preferential intergranular oxidation, and an intergranular cavitation creep.

It is difficult to distinguish the mechanism of the pre-mature EAC crack in its third initiation phase, i.e., in the slow growth, from the subsequent propagation of the mature EAC crack. It is expected that the crack development process transforms into a sequence of repeating steps where the specific key microprocesses persist.

Funding: This research was funded by the EC Horizon 2020 MEACTOS GA No. 755151, and by the Ministry of Education, Youth and Sport Czech Republic, grant number LQ1603; by the European Regional Development Fund (ERDF), grant number CZ.1.05/2.1.00/03.0108, and by the European Structural and Investment Funds (ESIF), grant number CZ.02.1.01/0.0/0.0/15_008/0000293.

Acknowledgments: This work was supported by the EC Horizon 2020 MEACTOS GA No. 755151. The presented work was financially supported by the Ministry of Education, Youth and Sport Czech Republic, project LQ1603 Research for SUSEN. This work was carried out within the SUSEN Project (established in the framework of the European Regional Development Fund (ERDF) in project CZ.1.05/2.1.00/03.0108 and of the European Structural and Investment Funds (ESIF) in the project CZ.02.1.01/0.0/0.0/15_008/0000293).

Conflicts of Interest: The author declares no conflict of interest.

\section{References}

1. de Curières, I. Corrosion in PWR Stainless Steel Components: A TSO perspective based on Operating Experience and Expertises. In Proceedings of the International Symposium Fontevraud 8, Avignon, France, 14-18 September 2014.

2. Ilevbare, G.O.; Cattant, F.; Peat, N.K. EAC of stainless steels under PWR service conditions. In Proceedings of the International Symposium Fontevraud 7, Avignon, France, 26-30 September 2010.

3. Andresen, P.L. A Brief History of Environmental Cracking in Hot Water. Corrosion 2019, 75, 240-253. [CrossRef]

4. Konings, R.J.M. Material Performance and Corrosion/Waste Materials. In Comprehensive Nuclear Materials; Elsevier: Amsterdam, The Netherlands, 2012; ISBN 978-0-08-056033-5.

5. Raja, V.S.; Shoji, T. Stress Corrosion Cracking: Theory and Practice; Woodhead Publishing Limited: Cambridge, UK, 2011; ISBN 978-085709-376-9.

6. Turnbull, A.; Mingard, K.; Lord, J.D.; Roebuck, B.; Tice, D.R.; Mottershead, K.J.; Fairweather, N.D.; Bradbury, A.K. Sensitivity of stress corrosion cracking of stainless steel to surface machining and grinding procedure. Corros. Sci. 2011, 53, 3398-3415. [CrossRef]

7. Chang, L.; Burke, M.G.; Scenini, F. Stress corrosion crack initiation in machined type 316L austenitic stainless steel in simulated pressurized water reactor primary water. Corros. Sci. 2018, 138, 54-65. [CrossRef] 
8. Chang, L.; Volpe, L.; Wang, Y.L.; Burke, M.G.; Maurotto, A.; Tice, D.; Lozano-Perez, S.; Scenini, F. Effect of machining on stress corrosion crack initiation in warm-forged type 304L stainless steel in high temperature water. Acta Mater. 2019, 165, $203-214$. [CrossRef]

9. Abe, H.; Watanabe, Y.; Miyazaki, T. Characteristics of Work Hardened Surface Layer on Austenitic Stainless Steels and Its Relation to EAC Susceptibility in High Temperature Water. In Proceedings of the 16th International Symposium on Environmental Degradation of Materials in Nuclear Power System-Water Reactors, Boston, MA, USA, 18-22 August 2019.

10. Chopra, O.K.; Rao, A.S. A Review of Irradiation Effects on LWR Core Internal Materials-IASCC Susceptibility and Crack Growth Rates of Austenitic Stainless Steels. J. Nucl. Mater. 2011, 409, 235-256. [CrossRef]

11. Scott, P.M.; Combrade, P. On the Mechanism of Stress Corrosion Crack Initiation and Growth in Alloy 600 Exposed to PWR Primary Water. In Proceedings of the 11th International Symposium on Environmental Degradation of Materials in Nuclear Power System-Water Reactors, Stevenson, WA, USA, 10-14 August 2003.

12. Couvant, T.; Legras, L.; Pokor, C.; Vaillant, F.; Brechet, Y.; Boursier, J.M.; Moulart, P. Investigations on The Mechanisms Of PWSCC Of Strain Hardened Austenitic Stainless Steels. In Proceedings of the 13th International Conference on Environmental Degradation of Materials in Nuclear Power Systems, Whistler, BC, Canada, 19-23 August 2007.

13. Ford, F.P. Mechanisms of environmentally-assisted cracking. Int. J. Press. Vessels Pip. 1989, 40, 343-362. [CrossRef]

14. Parkins, R.N. Metallography of environment sensitive fracture. Mater. Charact. 1991, 26, 303-323. [CrossRef]

15. Magnin, T.; Chieragatti, R.; Oltra, R. Mechanism of brittle fracture in a ductile 316 alloy during stress corrosion. Acta Metall. Mater. 1990, 38, 1313-1319. [CrossRef]

16. Shoji, T. Progress in the Mechanistic Understanding of BWR EAC and Its Implication to the Prediction of EAC Growth Behavior in Plants. In Proceedings of the 11th International Conference on Environmental Degradation of Materials in Nuclear Systems, Stevenson, WA, USA, 10-14 August 2003.

17. Shoji, T.; Lu, Z.; Murakami, H. Formulating stress corrosion cracking growth rates by combination of crack tip mechanics and crack tip oxidation kinetics. Corros. Sci. 2010, 52, 769-779. [CrossRef]

18. Lynch, S.P. Environmental assisted cracking: Overview of evidence for an adsorption-induced localised-slip process. Acta Metall. 1988, 36, 2639-2661. [CrossRef]

19. Lynch, S.P. Chap.1: Mechanistic and Fractographic Aspects of Stress-Corrosion Cracking. In Stress Corrosion Cracking: Theory and Practice; Woodhead Publishing Limited: Cambridge, UK, 2011.

20. Staehle, R.W. Introduction to initiation. In Proceedings of the Workshop on Detection, Avoidance, Mechanisms, Modelling, and Prediction of SCC Initiation in Water-Cooled Nuclear Reactor Plants, Beaune, France, 7-12 September 2008.

21. Zhai, Z.; Toloczko, M.B.; Olszta, M.J.; Bruemmer, S.M. Stress corrosion crack initiation of alloy 600 in PWR primary water. Corros. Sci. 2017, 123, 76-87. [CrossRef]

22. Seifert, H.P.; Hickling, J.; Lister, D. Corrosion and Environmentally-Assisted Cracking of Carbon and Low-Alloy Steels. In Comprehensive Nuclear Materials, Konings, R.J.M., Eds.; Elsevier: Amsterdam, The Netherlands, 2012; p. 110, ISBN 978-0-08-056033-5.

23. Arioka, K. Role of Cavity Formation on Long-Term Stress Corrosion Cracking Initiation: A Review. Corrosion 2020, 76, 142-175. [CrossRef]

24. Seifert, H.P.; Ritter, S.; Hickling, J. Environmentally-Assisted Cracking of Low-Alloy RPV and Piping Steels under LWR Conditions. In Proceedings of the 11th Int. Conf. Environmental Degradation of Materials in Nuclear Systems, Stevenson, WA, USA, 10-14 August 2003.

25. Seifert, H.P.; Ritter, S. Stress corrosion cracking of low-alloy reactor pressure vessel steels under boiling water reactor conditions. J. Nucl. Mater. 2008, 372, 114-131. [CrossRef]

26. Seifert, H.P.; Ritter, S. Strain-induced corrosion cracking behaviour of low-alloy steels under boiling water reactor conditions. J. Nucl. Mater. 2008, 378, 312-326. [CrossRef]

27. Roth, A.; Devrient, B.; Gómez-Briceño, D.; Lapeña, J.; Ernestová, M.; Žamboch, M.; Ehrnstén, U.; Föhl, J.; Weißenberg, T.; Seifert, H.-P.; et al. The Effect of Transients on the Crack Growth Behavior of Low Alloy Steels for Pressure Boundary Components Under Light Water Reactor Operating Conditions-CASTOC. In Proceedings of the 12th International Conference on Environmental Degradation of Materials in Nuclear Power System-Water Reactors, Salt Lake City, UT, USA, 14-18 August 2005.

28. Arioka, K.; Miyamoto, T.; Yamada, T.; Terachi, T. Formation of Cavities Prior to Crack Initiation and Growth on Cold-Worked Carbon Steel in High-Temperature Water. Corrosion 2010, 66, 015008-015008-14. [CrossRef]

29. Arioka, K.; Miyamoto, T.; Yamada, T.; Aoki, M. Role of Cavity Formation in Crack Initiation of Cold-Worked Carbon Steel in High-Temperature Water. Corrosion 2013, 69, 487-496. [CrossRef]

30. Arioka, K. 2014 W.R. Whitney Award Lecture: Change in Bonding Strength at Grain Boundaries Before Long-Term SCC Initiation. Corrosion 2015, 71, 403-419. [CrossRef]

31. Li, S.; Li, Y.; Lo, Y.-C.; Neeraj, T.; Srinivasan, R.; Ding, X.; Sun, J.; Qi, L.; Gumbsch, P.; Li, J. The interaction of dislocations and hydrogen-vacancy complexes and its importance for deformation-induced proto nano-voids formation in $\alpha$-Fe. Int. J. Plast. 2015, 74, 175-191. [CrossRef]

32. Birnbaum, H.K.; Sofronis, P. Hydrogen-enhanced localized plasticity-a mechanism for hydrogen-related fracture. Mater. Sci. Eng. 1994, A176, 191-202. [CrossRef]

33. Zhu, Y.; Li, Z.; Huang, M.; Fan, H. Study on interactions of an edge dislocation with vacancy-H complex by atomistic modelling. Int. J. Plast. 2017, 92, 31-44. [CrossRef] 
34. Magnin, T. The corrosion enhanced plasticity model for SCC in ductile fcc alloys. In Advances in Corrosion-Deformation Interactions (Material Science Forum); Trans Tech Publications Ltd.: Zurich, Switzerland, 1996; pp. 113-117.

35. Terachi, T.; Fujii, K.; Arioka, K. Microstructural characterization of SCC crack tip and oxide film for SUS 316 stainless steel in simulated PWR primary water at $320^{\circ} \mathrm{C}$. J. Nucl. Sci. Tech. 2005, 42, 225-232. [CrossRef]

36. Terachi, T.; Yamada, T.; Miyamoto, T.; Arioka, K.; Fukuya, K. Corrosion Behavior of Stainless Steels in Simulated PWR Primary Water-Effect of Chromium Content in Alloys and Dissolved Hydrogen. J. Nucl. Sci. Technol. 2008, 45, 975-984. [CrossRef]

37. Cissé, S.; Laffont, L.; Tanguy, B.; Lafont, M.-C.; Andrieu, E. Effect of surface preparation on the corrosion of austenitic stainless steel 304L in high temperature steam and simulated PWR primary water. Corros. Sci. 2012, 56, 209-216. [CrossRef]

38. Matthews, R.P.; Knusten, R.D.; Westraadt, J.E.; Couvant, T. Intergranular Oxidation of 316L Stainless Steel in the PWR Primary Water Environment. Corros. Sci. 2017, 125, 175-183. [CrossRef]

39. Arioka, K.; Iijima, Y.; Miyamoto, M. Acceleration of nickel diffusion by high tensile stress in cold-worked type 316 stainless steel at $450{ }^{\circ}$ C. Phil. Mag. 2018, 98, 2609-2617. [CrossRef]

40. Kruska, K.; Lozano-Perez, S.; Saxey, D.W.; Terachi, T.; Yamada, T.; Smith, G.D.W. Nanoscale characterisation of grain boundary oxidation in cold-worked stainless steels. Corros. Sci. 2012, 63, 225-233. [CrossRef]

41. Takazaki, D.; Tsuchiyama, T.; Komoda, R.; Dadfarnia, M.; Somerday, B.P.; Sofronis, P.; Kubota, M. Effect of Hydrogen on Creep Properties of SUS304 Austenitic Stainless Steel. Corrosion 2021, 177, 3678.

42. Devrient, B.; Kilian, R.; Kuster, K.; Widera, M. Influence of Bulk and Surface Cold Work on Crack Initiation and Crack Growth of Austenitic Stainless Steels under Simulated BWR Environment. In Proceedings of the 15th Int. Conf. on Environmental Degradation of Materials in Nuclear Power System, Colorado Springs, CO, USA, 19-23 August 2011.

43. Couvant, T.; Legras, L.; Herbelin, A.; Musienko, A.; Ilevbare, G.; Delafosse, D.; Cailletaud, G.; Hickling, J. Development of Understanding of the Interaction between Localized Deformation and EAC of Austenitic Stainless Steels Exposed to Primary PWR Environment. In Proceedings of the 14th International Conference on Environmental Degradation of Materials in Nuclear Power Systems, Virginia Beach, VA, USA, 23-27 August 2009.

44. Huang, Q.; Charles, Y.; Duhamel, C.; Gaspérini, M.; Crépin, J. Influence of the Combination of Microstructure and Mechanical Fields on Stress Corrosion Cracking Initiation of Cold-Worked Austenitic Stainless Steels. In Proceedings of the 19th International Conference on Environmental Degradation of Materials in Nuclear Power Systems-Water Reactors, Boston, MA, USA, 18-22 August 2019.

45. Hojná, A.; Halodová, P.; Janoušek, J.; Zimina, M. Accelerated Environmentally assisted cracking initiation of Type 316L steel in high temperature water and hydrogenated steam vapor environments. Corrosion 2020, 76, 1177-1193. [CrossRef]

46. Karlsen, W.; Diego, G.; Devrient, B. Localized deformation as a key precursor to initiation of intergranular stress corrosion cracking of austenitic stainless steels employed in nuclear power plants. J. Nucl. Mater. 2010, 406, 138-151. [CrossRef]

47. Couvant, T.; Burger, E.; Thaury, C.; Rainasse, C. Simulating the Susceptibility to IGEAC of Cold Work 316 Austenitic Stainless Steel Exposed to Primary Water. In Proceedings of the 19th International Conference on Environmental Degradation of Materials in Nuclear Power Systems-Water Reactors, Boston, MA, USA, 18-22 August 2019.

48. Panter, J.; Viguier, B.; Cloué, J.M.; Foucault, M.; Combrade, P.; Andrieu, E. Influence of oxide films on primary water stress corrosion cracking initiation of alloy 600. J. Nucl. Mater. 2006, 348, 213-221. [CrossRef]

49. Kuang, W.; Song, M.; Wang, P.; Was, G.S. The oxidation of alloy 690 in simulated pressurized water reactor primary water. Corros. Sci. 2017, 126, 227-237. [CrossRef]

50. Peng, Q.; Hou, J.; Sakaguchi, K.; Takeda, Y.; Shoji, T. Effect of dissolved hydrogen on corrosion of Inconel Alloy 600 in high temperature hydrogenated water. Electrochim. Acta 2011, 56, 8375-8386.

51. Fournier, L.; Calonne, O.; Combrade, P.; Scott, P.; Chou, P.; Pathania, R. Grain boundary oxidation and embrittlement prior to crack initiation in Alloy 600 in PWR primary water. In Proceedings of the 15th International Conference on Environmental Degradation of Materials in Nuclear Power Systems-Water Reactors, Colorado Springs, CO, USA, 7-11 August 2011.

52. Kim, T.; Choi, K.J.; Yoo, S.C.; Kim, J.H. Effects of dissolved hydrogen on the crack-initiation and oxidation behavior of nickel-based alloys in high-temperature water. Corros. Sci. 2016, 106, 260-270. [CrossRef]

53. Bertali, G.; Scenini, F.; Burke, M.G.; Huin, N. The effect of temperature on the preferential intergranular oxidation susceptibility of alloy 600. Metall. Mater. Trans. A 2018, 49, 1879-1894. [CrossRef]

54. Capell, B.M.; Was, G.S. Selective Internal Oxidation as a Mechanism of Intergranular Stress Corrosion cracking of Ni-Cr-Fe alloys. Metall. Mater. Trans. A 2007, 38, 1244-1259. [CrossRef]

55. Lim, Y.S.; Kim, S.W.; Hwang, S.S.; Kim, H.P.; Jang, C. Intergranular oxidation of Ni-based Alloy 600 in a simulated PWR primary water environment. Corros. Sci. 2016, 108, 125-133. [CrossRef]

56. Etien, R.A.; Richey, E.; Morton, D.S.; Eager, J. SCC Initiation Testing of Alloy 600 in High Temperature Water. In Proceedings of the 15th International Conference on Environmental Degradation of Materials in Nuclear Power System-Water Reactors, Colorado Springs, CO, USA, 19-23 August 2011.

57. Attanasio, S.A.; Morton, D.S. Measurement of the Nickel/Nickel Oxide Transition in Ni-Cr-Fe Alloys and Updated Data and Correlations to Quantify the Effect of Aqueous Hydrogen on Primary Water SCC. In Proceedings of the 11th International Conference on Environmental Degradation on Materials in Nuclear Power Systems-Water Reactors, Stevenson, WA, USA, 10-14 August 2003 
58. Bai, J.; Ritter, S.; Seifert, H.-P.; Virtanen, S. Stress corrosion cracking initiation and short crack growth behaviour in Alloy 182 weld metal under simulated boiling water reactor hydrogen water chemistry conditions. Corros. Sci. 2018, 131, 208-222. [CrossRef]

59. Arioka, K.; Staehle, R.W.; Yamada, T.; Miyamoto, T.; Terachi, T. Degradation of Alloy 690 After Relatively Short Times. Corrosion 2016, 72, 1252-1268. [CrossRef]

60. Zhai, Z.; Olszta, M.J.; Toloczko, M.B.; Bruemmer, S.M. Crack Initiation Behavior of Cold-Worked Alloy 690 in Simulated PWR Primary Water-Role of Starting Microstructure, Applied Stress and Cold Work on Precursor Damage Evolution. In Proceedings of the 16th International Symposium on Environmental Degradation of Materials in Nuclear Power System-Water Reactors, Boston, MA, USA, 18-22 August 2019.

61. Zhai, Z.; Toloczko, M.; Kruska, K.; Bruemmer, S.M. Precursor Evolution and Stress Corrosion Cracking Initiation of Cold-Worked Alloy 690 in Simulated Pressurized Water Reactor Primary Water. Corrosion 2017, 73, 1224-1236. [CrossRef]

62. Kuang, W.; Was, G.S. A high-resolution characterization of the initiation of stress corrosion crack in Alloy 690 in simulated pressurized water reactor primary water. Corros. Sci. 2020, 163, 108243. [CrossRef]

63. Moss, T.; Kuang, W.; Was, G.S. Stress corrosion crack initiation in Alloy 690 in high temperature water. Curr. Opin. Solid State Mater. Sci. 2018, 22, 16-25. [CrossRef] 